\title{
Genetic characterization of fluoroquinolone-resistant Escherichia coli associated with bovine mastitis in India
}

\author{
Sangeetha Balakrishnan ${ }^{1}$, Prabhakar Xavier Antony ${ }^{1}$, Hirak Kumar Mukhopadhyay ${ }^{1}$, Raghavan Madhusoodanan Pillai ${ }^{1}$,
} Jacob Thanislass ${ }^{2}$, Vijayalakshmi Padmanaban ${ }^{3}$ and Mouttou Vivek Srinivas ${ }^{1}$

1. Department of Veterinary Microbiology, Rajiv Gandhi Institute of Veterinary Education and Research, Puducherry - 605 009, India; 2. Department of Veterinary Biochemistry, Rajiv Gandhi Institute of Veterinary Education and Research, Puducherry - 605 009, India; 3. Department of Veterinary Medicine, Rajiv Gandhi Institute of Veterinary Education and Research, Puducherry - 605 009, India.

Corresponding author: Mouttou Vivek Srinivas, e-mail: vivekvet24@gmail.com,

SB: sangeethabvs@gmail.com, PXA: pxantony@gmail.com, HKM: mhirak@rediffmail.com,

RMP: drrmpillai@gmail.com, JT: jthanislass@gmail.com, VP: vijinethira@gmail.com

Received: 11-01-2016, Accepted: 03-06-2016, Published online: 11-07-2016

doi: 10.14202/vetworld.2016.705-709 How to cite this article: Balakrishnan S, Antony PX, Mukhopadhyay HK, Pillai RM, Thanislass J, Padmanaban V, Srinivas MV (2016) Genetic characterization of fluoroquinolone-resistant Escherichia coli associated with bovine mastitis in India, Veterinary World, 9(7): 705-709.

\begin{abstract}
Aim: The present study was undertaken to characterize the mutation in gyrA (DNA gyrase) and parC (topoisomerase IV) genes responsible for fluoroquinolone resistance in Escherichia coli isolates associated with the bovine mastitis.

Materials and Methods: A total of 92 milk samples from bovine mastitis cases were sampled in and around Puducherry (Southern India). Among these samples, 30 isolates were bacteriologically characterized as E. coli. Minimum inhibitory concentrations (MIC) of fluoroquinolones of these $30 \mathrm{E}$. coli isolates were evaluated by resazurin microtiter assay. Then, the quinolone resistance determining region (QRDR) (gyrA and parC genes) of these E. coli isolates was genetically analyzed for determining the chromosomal mutation causing fluoroquinolone resistance.

Results: E. coli isolates showed a resistance rate of $63.33 \%, 23.33 \%$ and $30.03 \%$ to nalidixic acid, ciprofloxacin and enrofloxacin, respectively. Mutations were found at $83^{\text {rd }}$ and $87^{\text {th }}$ amino acid position of gyr $A$ gene, and at $80^{\text {th }}$ and $108^{\text {th }}$ amino acid position of parC gene in our study isolates. Among these five isolates, one had a single mutation at 83 amino acid position of gyrA with reduced susceptibility $(0.5 \mu \mathrm{g} / \mathrm{ml})$ to ciprofloxacin. Then, in remaining four isolates, three isolates showed triple mutation (at gyrA: S83 $\rightarrow \mathrm{L}$ and $\mathrm{D} 87 \rightarrow \mathrm{N}$; at $\operatorname{parC}: \mathrm{S} 80 \rightarrow \mathrm{I}$ ) and the fifth isolate showed an additional mutation at codon 108 of parC $(\mathrm{A} 108 \rightarrow \mathrm{T})$ with the increased ciprofloxacin MIC of 16-128 $\mu \mathrm{g} / \mathrm{ml}$. The most common mutation noticed were at $\mathrm{S} 83 \rightarrow \mathrm{L}$ and $\mathrm{D} 87 \rightarrow \mathrm{N}$ of gyrA and $\mathrm{S} 80 \rightarrow \mathrm{I}$ of ParC.
\end{abstract}

Conclusion: The study confirms the presence of mutation/s responsible for fluoroquinolone resistance in QRDR of gyrA and $\operatorname{par} C$ genes of $E$. coli isolates of animal origin, and there is increased rate of fluoroquinolone resistance with high-level of MIC. The mutations observed in this study were similar to that of human isolates.

Keywords: Escherichia coli, fluoroquinolones, gyrA, parC, quinolone resistance determining region.

\section{Introduction}

Quinolones and fluoroquinolones are commonly used antimicrobial agent in both human and veterinary medicine due to its excellent safety profile and their broad spectrum activity against Gram-negative, Gram-positive, mycobacterial pathogen as well as anaerobes [1]. Resistance to quinolones is mainly due to a chromosomal mutation in DNA gyrase of gyrA and topoisomerase IV of parC gene, even though other mechanisms such as efflux pump and plasmid-mediated resistance are reported [2-5]. These chromosomal mutations are mostly noticed in the highly conserved domain of N-terminus region of gyrA and its analogs

Copyright: Balakrishnan, et al. Open Access. This article is distributed under the terms of the Creative Commons Attribution 4.0 International License (http://creativecommons.org/licenses/ by/4.0/), which permits unrestricted use, distribution, and reproduction in any medium, provided you give appropriate credit to the original author(s) and the source, provide a link to the Creative Commons license, and indicate if changes were made. The Creative Commons Public Domain Dedication waiver (http:// creativecommons.org/publicdomain/zero/1.0/) applies to the data made available in this article, unless otherwise stated. region of parC gene, known as quinolone resistance determining region (QRDR) [5-7].

Before the early 1990s, fluoroquinolone resistances are rarely noticed, but successful treatment outcomes resulted in an overuse of fluoroquinolones, led to an increased rate of resistance [8]. In countries like India, antimicrobial agents are widely used in food animals as a growth promoter. This non-therapeutic use of antibiotics especially fluoroquinolones are common and as such there is no proper regulation regarding the use of antibiotics in livestock industry [9]. Nowadays, the fluoroquinolone resistance has been reported worldwide $[3,10,11]$.

Hence, the present study was aimed at investigating the occurrence of fluoroquinolone resistance associated with bovine coliform mastitis in Puducherry (Southern India) and detecting the genetic mutations as well as correlations responsible for their resistance from Escherichia coli isolates of animal origin. 


\section{Materials and Methods}

\section{Ethical approval}

The approval from the Institutional Animal Ethics Committee (IAEC) to carry out this study was not required as no invasive technique was used. Milk samples were being collected from mastitis affected bovines from Veterinary hospitals and Veterinary Dispensaries in Puducherry.

\section{Isolation and identification of $\mathrm{E}$. coli}

A total of 92 milk samples were collected from mastitis affected bovines in Puducherry (Southern India) aseptically in sterile vials and cultured in MacConkey’s agar/Eosin methylene blue agar for isolation of the organism. The isolated Gram-negative bacteria were identified up to genus level based on the morphology, cultural and biochemical reactions. All the isolates were identified up to species level based on the standard bacteriological methods described by Barrow and Feltham [11] and were further confirmed by polymerase chain reaction (PCR) employing species-specific primer targeting the alanine racemase gene (alr gene) of E. coli [12] with the amplicon size of $366 \mathrm{bp}$ (Table-1). Isolates which were positive by species-specific PCR analysis were stored in glycerol Luria broth at $-40^{\circ} \mathrm{C}$ for further analysis.

\section{Fluoroquinolone susceptibility testing}

The minimum inhibitory concentration (MIC) of nalidixic acid, ciprofloxacin, and enrofloxacin were evaluated for the $30 \mathrm{E}$. coli isolates by resazurin microtiter assay, which is an indicator based broth microdilution method [13]. The test uses resazurin indicator, cation adjusted Mueller-Hinton broth, bacterial suspension with the concentration of $5 \times 10^{7} \mathrm{cfu} / \mathrm{ml}$ and E. coli ATCC 25922 as a control strain. The results were interpreted according to the performance and interpretative guidelines of the Clinical and Laboratory Standard institute [14].

\section{Genetic amplification of gyrA and parC genes}

Five isolates with different ciprofloxacin MIC ranging from 0.5 to $128 \mu \mathrm{g} / \mathrm{ml}$ were selected for genetic analysis of fluoroquinolone resistance. For genetic analysis, the QRDR of the gyrA gene and analogs parC genes was amplified (primers listed in Table-1) with the amplicon size of $190 \mathrm{bp}$ and $265 \mathrm{bp}$, respectively $[15,16]$. The template DNA from the $E$. coli isolates was extracted by boiling lysis method for the PCR assay [17]. The PCR-amplification of QRDR regions was carried out using $100 \mathrm{ng}$ template DNA, $5 \mu \mathrm{l} \times 10$ PCR buffer, $2 \mathrm{mM} \mathrm{MgCl}_{2}, 1 \mu \mathrm{l}$ of
$10 \mathrm{mM}$ deoxynucleotide triphosphates, $10 \mu \mathrm{M}$ of forward and reverse primers, 2U of Taq DNA Polymerase (New England Bio Labs) and the volume was made up to $50 \mu \mathrm{l}$ with nuclease free water. The template DNA from E. coli ATCC 25922 strain was used as positive control. The PCR amplification consisted of initial denaturation at $95^{\circ} \mathrm{C}$ for $5 \mathrm{~min}$ followed by 35 cycles of denaturation at $95^{\circ} \mathrm{C}$ for $30 \mathrm{~s}$, annealing at $55^{\circ} \mathrm{C}$ for $30 \mathrm{~s}$, and extension at $68^{\circ} \mathrm{C}$ for $1 \mathrm{~min}$, followed by a final extension at $68^{\circ} \mathrm{C}$ for $10 \mathrm{~min}$. The PCR amplified products were resolved on $1.5 \%$ agarose gel in tris acetate ethylenediaminetetraacetic acid buffer and visualized under ultraviolet transilluminator (Syngene, UK).

\section{Genetic analysis}

The amplified PCR products targeting two different genes for the five isolates were gel purified using a by Perfectprep gel cleanup kit (Eppendorf) and custom sequenced for both directions (5'-3' and 3'-5') with the same set of the primer pair, using the Automated Sequencer, Applied Biosystem 3100. The specificity of the sequences obtained, the nucleotide variations and amino acid variations with respect to the gyrA and parC genes sequence of $E$. coli strain were determined using basic local alignment search tool (http:// blast.ncbi.nlm.nih.gov/Blast.cgi). The obtained nucleotide sequences of gyrA and parC genes of five isolates were aligned with the sequence of $E$. coli K-12 MG1655 genome using ClustalW (www.ebi.ac.uk/ clustalw) and analyzed for the nucleotide variation in their gene. The 10 sequences ( 5 gyrA and 5 parC genes sequence) under the study were submitted in Genbank under the accession numbers JX446586, JX446587, JX446591, JX446592, JX446594 (gyrA gene); JX446596, JX446597, JX446601, JX446602, JX446604 (ParC gene).

\section{Results and Discussions}

Out of 92 milk samples collected from mastitis case, 30 were successfully isolated and confirmed to be E. coli with the species-specific PCR analysis (Figure-1).

\section{Fluoroquinolone susceptibility testing}

The MIC results for the $30 \mathrm{E}$. coli isolates to nalidixic acid, ciprofloxacin, and enrofloxacin were showed in Table-2. The MIC resistant breakpoint for nalidixic acid, ciprofloxacin, and enrofloxacin was $>32, \geq 4$, and $\geq 2 \mu \mathrm{g} / \mathrm{ml}$, respectively. The MIC value for nalidixic acid ranged from 4 to $>1024 \mu \mathrm{g} / \mathrm{ml}$. Of the 30

Table-1: Oligonucleotide primer sequence used for amplification of the following target gene in this study.

\begin{tabular}{lllc}
\hline Primers & Primer sequence & Target gene & Size (bp) \\
\hline Alr-F & 5'CTGGAAGAGGCTAGCCTGGACGAG3' & alr gene & Reference \\
Alr-R & 5'AAAATCGGCACCGGTGGAGCGATC3' bp & [12] \\
GyrA-F & 5'ACGTACTAGGCAATGACTGG3' & gyrA gene & [16] bp \\
GyrA-R & 5'AGAAGTCGCCGTCGATAGAAC3' & & parC gene \\
ParC-F & 5'TGTATGCGATGTCTGAACTG3' & bp \\
ParC-R & 5'CTCAATAGCAGCTCGGAATA3' & & \\
\hline
\end{tabular}




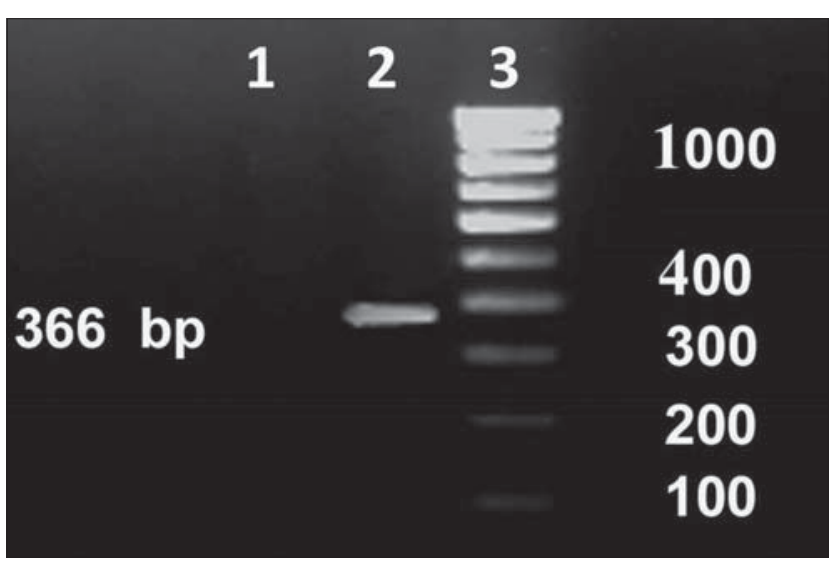

Figure-1: Screening of isolates for detection of Escherichia coli using species-specific primers targeting the alanine racemase gene (alr gene). Lane 1: Negative isolate, Lane 2: Positive isolate, Lane 3: DNA ladder.

Table-2: MIC value of E. coli isolates from bovine mastitis milk in this study.

\begin{tabular}{|c|c|c|c|}
\hline \multirow[t]{2}{*}{ Isolate } & \multicolumn{3}{|c|}{ MIC $(\mu \mathrm{g} / \mathrm{ml})$} \\
\hline & Nalidixic acid & Ciprofloxacin & Enrofloxacin \\
\hline CM1 & $>1024$ & 128 & 512 \\
\hline $\mathrm{CM} 2$ & 1024 & 2 & 0.125 \\
\hline CM3 & 8 & 0.0625 & 0.0625 \\
\hline CM4 & 1024 & 0.5 & 4 \\
\hline CM5 & 64 & 0.25 & 0.25 \\
\hline CM6 & 1024 & 0.5 & 8 \\
\hline CM7 & 16 & 0.5 & 0.5 \\
\hline M2 & 16 & 2 & 0.03 \\
\hline M3 & 16 & 0.25 & 0.25 \\
\hline SM3 & 16 & 0.25 & 0.25 \\
\hline BM1 & 16 & 0.25 & 0.25 \\
\hline BM7 & 1024 & 0.5 & 0.5 \\
\hline KM1 & 4 & 0.06 & 0.06 \\
\hline TVM8 & 1024 & 32 & 128 \\
\hline AM1 & 8 & 0.0625 & 0.0625 \\
\hline AM2 & 8 & 0.0625 & 0.0625 \\
\hline AM3 & 256 & 2 & 1 \\
\hline AM4 & 1024 & 2 & 2 \\
\hline AM5 & 1024 & 0.5 & 1 \\
\hline AM6 & 1024 & 16 & 32 \\
\hline AM7 & $>1024$ & 128 & 256 \\
\hline AM8 & 1024 & 2 & 1 \\
\hline AM9 & 1024 & 32 & 128 \\
\hline AM10 & 1024 & 1 & 0.5 \\
\hline AM11 & 1024 & 8 & 32 \\
\hline AM12 & 1024 & 16 & 64 \\
\hline SMM6 & 16 & 0.5 & 0.5 \\
\hline MM1 & 4 & 0.06 & 0.06 \\
\hline MM5 & 64 & 0.25 & 0.25 \\
\hline MM8 & 1024 & 0.5 & 1 \\
\hline
\end{tabular}

E. coli=Escherichia coli, MIC=Minimum inhibitory concentrations

E. coli isolates, $17(56.67 \%)$ isolates required MIC of $\geq 256 \mu \mathrm{g} / \mathrm{ml}$ and $2(6.67 \%)$ isolates required $64 \mu \mathrm{g} / \mathrm{ml}$ nalidixic acid for inhibition of growth, and remaining 11 isolates showed MIC of $4-16 \mu \mathrm{g} / \mathrm{ml}$, which is below the resistance breakpoint. The MIC value for ciprofloxacin ranged from 0.0625 to $128 \mu \mathrm{g} / \mathrm{ml}$. Out of 30 E. coli isolates, $7(23.33 \%)$ isolates were resistant to ciprofloxacin, which required $4-128 \mu \mathrm{g} / \mathrm{ml}$ of ciprofloxacin for inhibition of $E$. coli. The MIC value for enrofloxacin ranged from 0.03 to $512 \mu \mathrm{g} / \mathrm{ml}$. Of the 30 E. coli strains, $10(30.03 \%)$ isolates were found to be resistant to enrofloxacin, which required $2-512 \mu \mathrm{g} / \mathrm{ml}$ of enrofloxacin for inhibition. 7 (23.33\%) isolates were cross-resistant to ciprofloxacin as well as to enrofloxacin. In 2010, Ranjan et al. [18] reported low fluoroquinolone resistance rate with the cure rates of $91.67 \%$ for enrofloxacin and $90.15 \%$ for ciprofloxacin $(90.15 \%)$ in the treatment of clinical bovine mastitis, whereas, in our study, $63.33 \%$ of the E. coli isolates were resistant to nalidixic acid, $23.33 \%$ to ciprofloxacin and $30.03 \%$ to enrofloxacin, which is in increasing side. It is observed that 19 isolates which were resistant to nalidixic acid ( $\geq 32 \mu \mathrm{g} / \mathrm{ml}$ to $\geq 1024 \mu \mathrm{g} / \mathrm{ml}$ ), showed either resistance or reduced susceptibility to fluoroquinolones used in our study. According to Livemore [19], isolates with reduced susceptibility to fluoroquinolones may become resistant in the period of time and evolution of such reduced susceptibility to quinolone is a serious concern due to rapid rising rates of fluoroquinolone resistance in many parts of the world. Resistance to one fluoroquinolone may confer resistance to other fluoroquinolones [20]. In our study, $23.33 \%$ of the isolates were cross-resistance to ciprofloxacin as well as enrofloxacin.

\section{Genetic analysis}

Sequence analysis of the $190 \mathrm{bp}$ PCR product size covering the QRDR of gyrA showed the presence of mutation at codon $83 \mathrm{Ser} \rightarrow$ Leu (TCG $\rightarrow$ TTG) of gyrA gene in all five isolates sequenced (Figure-2a). Several studies reports that the substitution at codon 83 is the most common and consistent mutation found in the fluoroquinolone-resistant E. coli strains $[3,17,20]$. Four out of five isolates (except CM4) also had a second mutation at $87^{\text {th }}$ codon Asp $\rightarrow$ Asn of gyrA gene (GAC $\rightarrow$ AAC). Mutation at these two codons ( $83^{\text {rd }}$ and $87^{\text {th }}$ codon) of GyrA protein is responsible for causing high-level of quinolone resistance than the mutation at other codons within the QRDR [20].

With respect to parC, isolate CM4, which had a single mutation in gyrA did not have any mutation in QRDR of parC gene, whereas the rest four isolates having double mutation in gyrA gene also had mutation/s in parC gene (Figure-2b). Among five isolates, four had a third mutation at codon $80 \mathrm{Ser} \rightarrow \mathrm{Ile}$ (AGC $\rightarrow$ ATC) of QRDR of parC gene, which is analogous to $87^{\text {th }}$ codon of gyrA gene. Out of four isolates bearing a third mutation in parC, one isolates (CM1) had a fourth mutation at $108^{\text {th }}$ codon Ala $\rightarrow \mathrm{Thr}$ (GCG $\rightarrow$ ACG). One isolates (CM4) with a single mutation in gyrA did not exhibit any mutation in parC. This is because according to the currently accepted alternating-target model, highlevel fluoroquinolone resistance in E. coli develops by stepwise acquisition of target mutations, in which DNA gyrase is the primary target and topoisomerase IV is the secondary target for fluoroquinolones in E. coli [21-23]. Most common mutation noticed were 
at $\mathrm{S} 83 \rightarrow \mathrm{L}$ and $\mathrm{D} 87 \rightarrow \mathrm{N}$ of gyrA and $\mathrm{S} 80 \rightarrow \mathrm{I}$ of ParC in our study (Table-3).

The relationship between the number of mutation/s and their MIC values are shown in Table-3. The correlation between MIC value and mutation pattern were investigated to determine the potential mechanism of fluoroquinolone resistance. The previous studies by different researchers [23] suggest that there is correlation between the number of changes in gyrA and $\operatorname{par} C$ genes and the level of quinolone resistance in E. coli strains. Although our study is small to explain the correlation, it is noticed that isolate with single mutation in gyrA and no mutation in parC showed low-level of fluoroquinolone resistance with ciprofloxacin MIC of $0.5 \mu \mathrm{g} / \mathrm{ml}$ and enrofloxacin MIC of $4 \mu \mathrm{g} / \mathrm{ml}$, whereas isolates with three mutations (two in gyrA and one in parC) were associated with moderate to high level of resistance to fluoroquinolone with $\mathrm{MIC}$ of ciprofloxacin and enrofloxacin ranging from

Table-3: MIC values and amino acid variations at QRDR (gyrA and parC gene) of fluoroquinolone-resistant E. coli isolates.

\begin{tabular}{|c|c|c|c|c|c|c|c|}
\hline \multirow[t]{3}{*}{ Isolate } & \multirow{2}{*}{\multicolumn{3}{|c|}{$\operatorname{MIC}(\mu \mathrm{g} / \mathrm{ml})$}} & \multicolumn{4}{|c|}{ Amino acid variation } \\
\hline & & & & \multicolumn{2}{|c|}{ gyrA gene } & \multicolumn{2}{|c|}{ parC gene } \\
\hline & NAL & CIP & ENR & 83 & 87 & 80 & 108 \\
\hline \multicolumn{4}{|c|}{ Reference strain (49175990a) } & $\mathrm{S}$ & $\mathrm{D}$ & $\mathrm{S}$ & $A$ \\
\hline CM4 & 1024 & 0.5 & 4 & $\mathrm{~L}$ & $\mathrm{D}$ & $\mathrm{S}$ & $A$ \\
\hline AM6 & 1024 & 16 & 32 & $\mathrm{~L}$ & $\mathrm{~N}$ & I & A \\
\hline TVM8 & 1024 & 32 & 128 & $\mathrm{~L}$ & $\mathrm{~N}$ & 1 & A \\
\hline AM7 & $>1024$ & 128 & 256 & $\mathrm{~L}$ & $\mathrm{~N}$ & I & $A$ \\
\hline CM1 & $>1024$ & 128 & 512 & $\mathrm{~L}$ & $\mathrm{~N}$ & 1 & $\mathrm{~T}$ \\
\hline
\end{tabular}

${ }^{a}$ Reference strain GenBank accession ID, NAL=Nalidixic acid, $\mathrm{CIP}=$ Ciprofloxacin, ENR=Enrofloxacin, $\mathrm{S}=$ Serine, $\mathrm{L}=$ leucine, $\mathrm{D}=$ Aspartic acid, $\mathrm{N}=$ Asparagine, $\mathrm{I}=$ I soleucine, $\mathrm{A}=$ Alanine, $\mathrm{T}=$ Threonine, $\mathrm{QRDR}=$ Quinolone resistance determining region, E. coli=Escherichia coli, $\mathrm{MIC}=$ Minimum inhibitory concentrations
16 to $128 \mu \mathrm{g} / \mathrm{ml}$ and $32-256 \mu \mathrm{g} / \mathrm{ml}$, respectively. One isolate with four mutations (two in gyrA and two in parC) showed the highest level of resistance to fluoroquinolone with ciprofloxacin and enrofloxacin MIC of 128 and $512 \mu \mathrm{g} / \mathrm{ml}$; respectively. The amino acid substitutions observed, in this study, were similar to that of mutations reported from isolates of human origin [24].

\section{Conclusion}

Antimicrobial agents have been used in livestock and poultry since the early 1950 s to treat infection, improve growth and feed efficiency [18]. Overuse and misuse of antimicrobial agent led to an increased antimicrobial resistance around the world leading to treatment failures in infectious diseases of human and animal. Mutations in QRDR of gyrA and parC genes are important for developing high-level of fluoroquinolone resistance in E. coli isolates. The present study revealed the prevalence of fluoroquinolone resistance in E. coli of animal origin. There is increased rate of fluoroquinolone resistance with high-level of MIC and presence of chromosomal mutation/s at QRDR (gyrA and parC genes) of fluoroquinolone-resistant $E$. coli isolates of bovine mastitis milk samples. These mutation patterns from the animal isolate were similar to that of human isolate with no significant differences.

\section{Authors' Contributions}

SB and PXA were involved in the design of this research work. The research was done by SB. PXA has monitored all the activities being a supervisor. HKM, RMP, JT, and VP have assisted this research work. SB and MVS drafted and revised the manuscript. All authors read and approved the final manuscript.

\section{Acknowledgments}

The authors are grateful to the Dean, Rajiv Gandhi Institute Veterinary Education and Research,

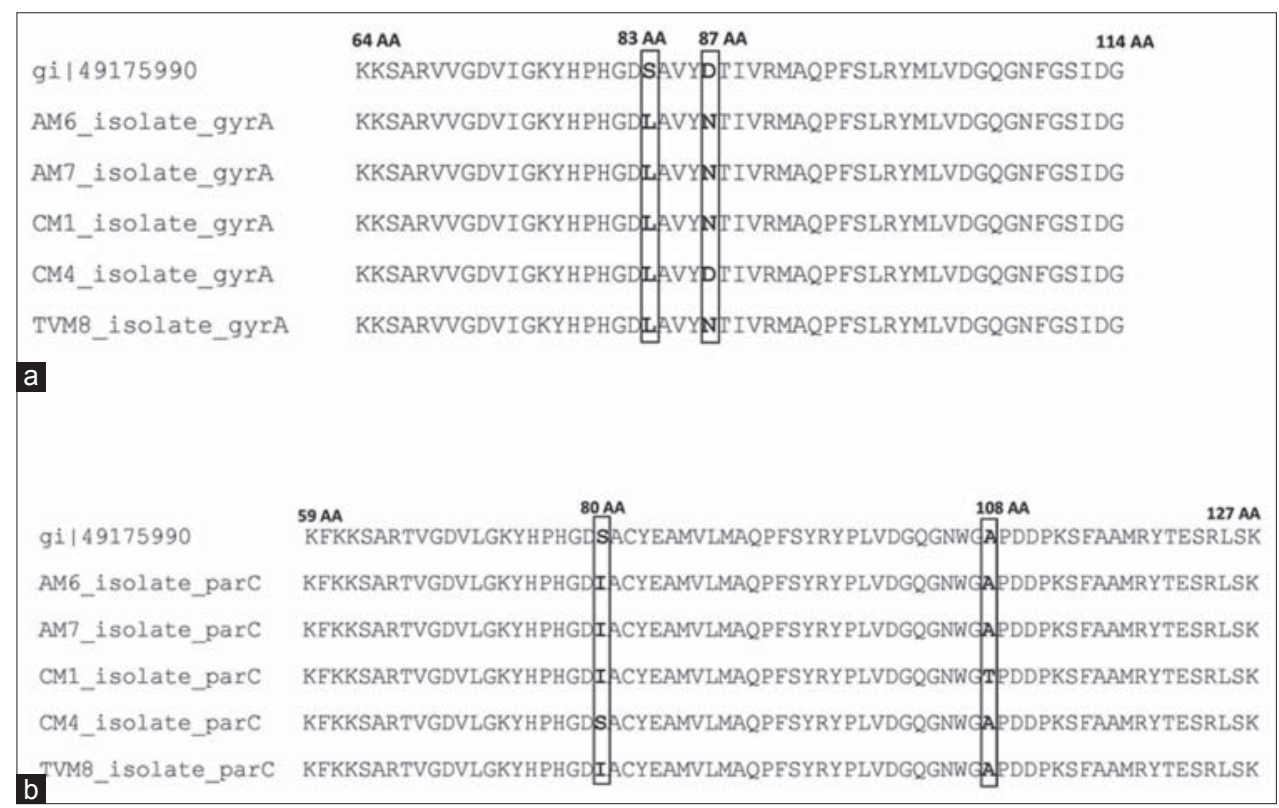

Figure-2: Amino acid variation of (a) gyrA gene and (b) parC gene of five Escherichia coli isolates under this study and wild type E. coli reference strain (49175990) available in GenBank. 
Kurumbapet, Pondicherry, India for providing necessary facilities and fund to conduct this research.

\section{Competing Interests}

The authors declare that they have no competing interests.

\section{References}

1. Takahashi, H., Hayakawa, I. and Akimoto, T. (2003) The history of the development and changes of quinolone antibacterial agents. Yakushigaku Zasshi, 38: 161-179.

2. Hooper, D.C. (1999) Mechanisms of fluoroquinolone resistance. Drug Resist. Updat., 2: 38-55.

3. Pazhani, G.P., Chakraborty, S., Fujihara, K., Yamasaki, S., Ghosh, A., Nair, G.B. and Ramamurthy, T. (2011) QRDR mutations, efflux system \& antimicrobial resistance genes in enterotoxigenic Escherichia coli isolated from an outbreak of diarrhoea in Ahmedabad, India. Indian J. Med. Res., 134: 214-223.

4. Vanni, M., Meucci, V., Tognetti, R., Cagnardi, P., Montesissa, C., Piccirillo, A., Rossi, A.M., Di Bello, D. and Intorre, L. (2014) Fluoroquinolone resistance and molecular characterization of gyrA and parC quinolone resistance-determining regions in Escherichia coli isolated from poultry. Poult. Sci., 93(4): 856-863.

5. Uchida, Y., Mochimaru, T., Morokuma, Y., Kiyosuke, M., Fujise, M., Eto, F., Harada, Y., Kadowaki, M., Shimono, N. and Kang, D. (2010) Geographic distribution of fluoroquinolone-resistant Escherichia coli strains in Asia. Int. J. Antimicrob. Agents, 35(4): 387-391.

6. Betitra, Y., Teresa, V., Miguel, V. and Abdelaziz, T. (2014) Determinants of quinolone resistance in Escherichia coli causing community acquired urinary tract infection in Bejaia, Algeria. Asian Pac. J. Trop. Med., 7(6): 462-467.

7. Liu, B.T., Liao, X.P., Yang, S.S., Wang, X.M., Li, L.L., Sun, J., Yang, Y.R., Fang, L.X., Li, L., Zhao, D.H. and Liu, Y.H. (2012) Detection of mutations in the gyrA and parC genes in Escherichia coli isolates carrying plasmid-mediated quinolone resistance genes from diseased food-producing animals., J. Med. Microbiol., 61(11): 1591-1599.

8. Wasyl, D. (2014) Prevalence and characterization of quinolone resistance mechanisms in commensal Escherichia coli isolated from slaughter animals in Poland, 2009-2012. Microb. Drug Resist., 20(6): 544-549.

9. Mavroidi, A., Miriagou, V., Liakopoulos, A., Tzelepi, E., Stefos, A., Dalekos, G.N. and Petinaki, E. (2012) Ciprofloxacin-resistant Escherichia coli in Central Greece: Mechanisms of resistance and molecular identification. BMC Infect. Dis., 12: 371.

10. El-Sokkary, M.M.A. and Abdelmegeed, E.S. (2015) Antibacterial resistance pattern among Escherichia coli strains isolated from Mansoura hospitals in Egypt with special reference to qunionlones. Afr. J. Med. Res., 9(9): 662-670.

11. Barrow, G.I. and Feltham, R.K.A. (2003) Characters of gram negative bacteria. Cowan and Steel's Manual for the Identification of Medical Bacteria. $3^{\text {rd }}$ ed. Cambridge
University, Cambridge, UK. p94-149.

12. Yokoigawa, K., Inoue, K., Okubo, Y. and Kawai, H. (1999) Primers for amplifying an alanine racemase gene fragment to detect Escherichia coli strain in foods. J. Food Sci., 64: 571-575.

13. Sarker, S.D., Nahar, L. and Kumarasamy, Y. (2007) Microtitre plate-based antibacterial assay incorporating Resazurin as an indicator of cell growth, and its application in the in vitro antibacterial screening of phytochemicals. Methods, 42: 321-324.

14. Abdi-Hachesoo, B., Asasi, K. and Sharifiyazdi, H. (2013) Rapid detection of Escherichia coli gyrA and parC mutants in one-day-old broiler chicks in Iran. Vet. Ital., 49(3): 291-297.

15. Zhang, K., Sparling, J., Chow, B.L., Elsayed, S., Hussain, Z., Chruch, D.L., Gregson, D.B., Louie, T. and Conly, J.M. (2004) New quadriplex PCR assay for detection of methicillin and mupirocin resistance and simultaneous discrimination of S. Aureus from coagulase-negative Staphylococci. J. Clin. Microbiol., 42: 4947-4955.

16. Everett, M.J., Fang-Jin, Y., Ricci, V. and Piddock, L.J.V. (1996) Contributions of individual mechanisms to fluoroquinolone resist resistance in 36 Escherichia coli strains isolated from humans and animals. Antimicrob. Agents Chemother., 40: 2380-2386.

17. Aarestrup, F.M., Wegener, H.C. and Collignon, P. (2008) Resistance in bacteria of the food chain: Epidemiology and control strategies. Exp. Rev. Anti. Infect. Ther., 6: 733-750.

18. Ranjan, R., Gupta, M.K., Satparkash, S. and Kumar, S. (2010) Current trend of drug sensitivity in bovine mastitis. Vet. World, 3: 17-20.

19. Livemore, D.M. (2009) Has the era of untreatable infections arrived? J. Antimicrob. Chemother., 64: 29-36.

20. Hopkins, K.L., Davies, R.H. and Threlfall, E.J. (2005) Mechanisms of quinolone resistance in Escherichia coli and Salmonella: Recent developments. Int. J. Antimicrob. Agents, 25: 358-373.

21. Al-Agamy, M.H.M., Shibl, A.M. and Radwan, H.H. (2012) Detection of mutations in quinolone-resistant determining regions in clinical isolates of Escherichia coli from Saudi Arabia. Afr. J. Biotechnol., 11(5): 1054-1058.

22. Meireles, D., Leite-Martins, L., Bessa, L.J., Cunha, S., Fernandes, R., de Matos, A., Manaia, C.M. and da Costa, P.M. (2015) Molecular characterization of quinolone resistance mechanisms and extended-spectrum $\beta$-lactamase production in Escherichia coli isolated from dogs. Comp. Immunol. Microbiol. Infect. Dis., 41: 43-48.

23. Zhao, H.X., Zhao, J.L., Shen, J.Z., Fan, H.L., Guan, H., An, X.P. and Li, P.F. (2014) Prevalence and molecular characterization of fluoroquinolone resistance in Escherichia coli isolates from dairy cattle with endometritis in China. Microb. Drug Resist., 20(2): 162-169.

24. Ishiguro, F., Toho, M., Yamazaki, M., Matsuyuki, S., Moriya, K., Tanaka, D., Isobe, J., Kyota, Y. and Muraoka, M. (2006) Mutations of gyrA gene and parC gene in fluoroquinolone-resistant Escherichia coli isolates from sporadic diarrheal cases. Kansenshogaku Zasshi, 80: 507-512. 